\title{
Histamine Poisoning by Bacteria
}

\author{
Debarshi Dasgupta* \\ Department of Agricultural Microbiology, University of Agricultural Sciences, \\ GKVK, Bengaluru-560065, India \\ *Corresponding author
}

Histamine poisoning is a food-borne chemical intoxication resulting from the ingestion of foods that contain unusually high levels of histamine, which crosses the intestinal barrier of mammals. It occurs mainly by consumption of fish belonging to Scombridae and Scomberesocidae families (eg: tuna, mackerel, bonito, skipjack etc.), nonscombroid fish (sardine, bluefish etc.), Swiss cheese, sauerkraut, ham and others. Time and temperature abuse in fish can cause scombrotoxin formation where histamine levels can go upto 50 to $500 \mathrm{ppm}$ or more. Symptoms include diarrhea, vomiting, dizziness, flushing etc. (Taylor, 1986).

When food items are inadequately frozen, it allows certain bacteria to thrive. These bacteria produce decarboxylases that act on amino acids to produce histamine and other biogenic amines like putrescine, cadaverine, spermidine and spermine. Another more common catabolic pathway involves loss of ammonia from histidine by action of Lhistidine ammonia lyase (HAL) to form urocanic acid, which acts as a mast cell degranulator, thus augmenting histamineeffect. Hence it is often referred to the "missing factor" in histamine fish poisoning.
Diamine oxidase (DAO) and histamine methyl transferase (HMT) function in detoxifying histamine (Baranowski, 1985).

Cadaverine and other biogenic amines inhibit DAO and HMT, acting as potentiators for histamine, justifying the potentiatorhypothesis which implies that consumption of spoiled fish is more dangerous than intake of pure histamine orally. Potentiators also enhance absorption of histamine in intestines. Paralytic shellfish poisons (saxitoxins) are responsible for scombrotoxicosis (Lyons et al., 1983).

Histidine-decarboxylating bacteria include members of family Enterobacteriaceae (like Morganella morganii, Klebsiella pneumoniae and Hafnia alvei), Clostridium sp. and Lactobacillus sp. in cheese. Histamine production by these microbes is increased when stored at a temperature of $4^{\circ} \mathrm{C}$ or more. They are halophilic or halotolerantand are mainly found in the gills and intestines of the fish (Behling and Taylor, 1982).

The key to keeping bacteria and histamine levels low is the rapid cooling of fish after catching and the maintenance of adequate 
refrigeration during handling and storage, until the time of cooking and final consumption. Most of the microflora of fish seems to be derived post-catching, due to faulty receiving in fishing vessel, processing, packaging, final chilling and storage.

Antihistamine drugs are administered as the basis of treatment. Basically, drugs like diphenhydramine, cetirizine, cimetidine etc. are antagonists of $\mathrm{H} 1$ or $\mathrm{H} 2$ receptors. Patient under DAO and MAO inhibitor treatment are obviously more prone to be poisoned.

Despite the huge expansion in trade in recent years, substantial progress has been made in ensuring quality and safety of fish products. This is largely the result of the introduction of international standards of food hygiene and the applications of risk analysis and HACCP (Hazard Analysis and Critical Control Points) principles (Lehane and Olley, 2000). Subsequently, bodies like FSSAI (Food Safety and Standards Authority of India) have been revising the list of fish species which can cause histamine poisoning and setting limits of histamine levels in fishery products.

\section{References}

Baranowski, J. D., 1985, Low-temperature production of urocanic acid by spoilage bacteria isolated from mahi-mahi (Coryphaena hippurus). Appl. Environ. Microbiol., 50(2): 546-547.

Behling, A. R. and Taylor, S. L., 1982, Bacterial histamine production as a function of temperature and time of incubation. J .Food Sci., 47: 13111317.

Lehane, L. and Olley, J., 2000, Histamine fish poisoning revisited. Int. J. Food Microbiol., $58: 1-37$

Lyons, D. E., Beery, J. T., Lyons, S. A. and Taylor, S. L. 1983, Cadaverine and aminoguanidine potentiate the uptake of histamine in vitro in perfused intestinal segments of rats. Toxicol. Appl. Pharmacol., 70: 445-458.

Taylor, S. L., 1986, Histamine food poisoning: toxicology and clinical aspects. Crit. Rev. Toxicol., 17(2): 91128.

\section{How to cite this article:}

Debarshi Dasgupta. 2020. Histamine Poisoning by Bacteria. Int.J.Curr.Microbiol.App.Sci. 9(08): 3457-3458. doi: https://doi.org/10.20546/ijcmas.2020.908.400 